\title{
EDITORIAL
}

\section{LA INVESTIGACIÓN COMO HERRAMIENTA DE LA GESTIÓN DEL CUIDADO}

$\mathrm{n}$ el contexto del proceso de reforma sanitaria, la profesión de enfermería se
encuentra en un momento histórico y al mismo tiempo crucial que le obliga a generar conocimientos propios que sustenten la responsabilidad asignada de "gestión del cuidado de enfermería", entendida como el ejercicio profesional sustentado en su disciplina.

En esta concepción dirigida a la gestión del cuidado se requiere desarrollar investigación basada en evidencias científicas, así como de una estructura del sistema de salud que favorezca la práctica de enfermería hacia el cuidado y se produzcan las transformaciones que muestren un quehacer profesional y humanizado. Las interrogantes que surgen en este proceso deben ser resueltas mediante la investigación, para generar y/o contrastar conocimientos destinados a contribuir a mejorar el cuidado en salud, lo que distingue al saber y al hacer de enfermería, lo que a su vez confiere autonomía profesional para diagnosticar necesidades de cuidado y tomar decisiones con responsabilidad ética y legal.

Siendo la enfermera responsable de la gestión debe considerar los valores, actitudes y conocimientos de la disciplina que le brindan una visión distinta y específica de su labor, pues ésta se ejerce no solamente con los recursos que dan las teorías de la administración, sino también con las relaciones y concepciones propias de la disciplina de enfermería.

En este ámbito la Revista Ciencia y Enfermería se constituye en un valioso aporte para evidenciar y mostrar estrategias e intervenciones que favorezcan el actuar eficiente de los servicios de enfermería en los ámbitos sanitarios de nuestro quehacer. 